\title{
Fast deposition of diamond-like carbon films by radio frequency hollow cathode method
}

\author{
Xiaolu Pang a , Haili Peng a , Huisheng Yang a,*, Kewei Gao ${ }^{\text {a }}$, Xiaolei Wu ${ }^{\text {b }}$, Alex A. Volinsky ${ }^{\mathrm{c}}$ \\ a Department of Materials Physics and Chemistry, University of Science and Technology Beijing, Beijing 100083, China \\ b State Key Laboratory of Nonlinear Mechanics, Chinese Academy of Sciences, Beijing 100080, China \\ c Department of Mechanical Engineering, University of South Florida, Tampa, FL 33620, USA
}

\section{A R T I C L E I N F O}

\section{Article history:}

Received 1 June 2012

Received in revised form 23 February 2013

Accepted 25 February 2013

Available online 6 March 2013

\section{Keywords:}

Diamond-like carbon films

Hollow cathode

Deposition rate

Raman spectra

Nanohardness

\begin{abstract}
A B S T R A C T
Diamond-like carbon (DLC) thin films were deposited on p-type Si (100) substrates by RF hollow cathode method under different RF power and pressure, using ethane as the precursor gas. The deposition rate of $45 \mathrm{~nm} / \mathrm{min}$ was achieved, almost 4 times higher than by conventional radio frequency plasma enhanced chemical vapor deposition. The mechanism of fast DLC films deposition is attributed to high plasma density in RF hollow cathode method, discussed in this paper. Scanning electron microscopy and Raman spectroscopy were used to investigate the microstructure of DLC films. The film hardness and Young's modulus were measured by nanoindentation.
\end{abstract}

(c) 2013 Elsevier B.V. All rights reserved.

\section{Introduction}

Diamond-like carbon (DLC) films consist of amorphous carbon with $\mathrm{sp}^{3}$ and $\mathrm{sp}^{2}$ bonds. These films are similar to diamond, and generally include many $\mathrm{sp}^{3}$ bonds. If the amount of hydrogen contained in a film is reduced, and the ratio of $\mathrm{sp}^{3}$ to $\mathrm{sp}^{2}$ bonds is increased, DLC usually becomes harder. DLC films deposited at low temperatures are extremely smooth. The coefficient of friction changes with the measurement conditions, and can be as low as 0.1 , or even less, in dry or humid air, or in nitrogen [1-3]. Although DLC films have excellent mechanical properties, a practical problem with them is that the residual stress increases with the hardness [4]. When the adhesion between the film and the substrate is not sufficient, the film can partially ablate. An improvement of the adhesion with a substrate has been studied along with the problem of thermal stability [5,6]. Metal-containing diamond-like carbon (Me-DLC) is a DLC film, in which nano-scale metal clusters are dispersed homogeneously, possibility solving the above noted problems. Metal clusters effectively decrease the residual stress in DLC films. The tribological properties of the Me-DLC in dry sliding wear have been reported $[5,7,8]$. However, the hardness of a thin film generally drops with the amount of metal inclusions, and damage to the film by abrasion will increase, rather than damage by ablation.

With improving deposition technology, DLC films are widely used in many industries because of their high hardness, low friction coefficient, good wear resistance, smoothness, etc. For most products, reliability

\footnotetext{
* Corresponding author.

E-mail address: pangxl@mater.ustb.edu.cn (H. Yang).
}

and production efficiency are very important factors for their wide use. Increasing the deposition rate is one way to reduce manufacturing time and, hence, manufacturing cost. Intrinsic stress in Me-DLC films is efficiently relieved, and thus their reliability in service is improved [9-11], although the deposition rate of DLC films needs to be studied further.

There are many ways to prepare DLC films [12-15]. The radio frequency plasma enhanced chemical vapor deposition (RF-PECVD) process is widely used. However, this method suffers from a low deposition rate, due to the low plasma density. In previous work, DLC films were prepared using PECVD with a deposition rate of 4-10 $\mathrm{nm} / \mathrm{min}$ [16]. Z. Sun et al. [17] reported an improved method, called magnetically enhanced plasma chemical vapor deposition, to increase the density of plasma, based on PECVD, which gave a deposition rate $5-23 \mathrm{~nm} / \mathrm{min}$. Other techniques, based on high plasma density, are also used to produce DLC films, like plasma source ion implantation [18,19], with a deposition rate of $75-150 \mathrm{~nm} / \mathrm{h}$. An election cyclotron wave resonance source was employed to prepare DLC films with a very high deposition rate of $20-90 \mathrm{~nm} / \mathrm{min}$ by applying magnetic field [20], but the corresponding apparatus is relatively complicated and expensive.

In this work, DLC films were deposited using radio frequency hollow cathode deposition system, based on conventional RF-PECVD. Here, comparatively high plasma density was achieved using a simple construction without magnets, utilizing hollow cathode effect through parallel plates to constrain plasma in a certain area. The basic principle of the hollow cathode glow discharge is the overlap of the negative glow zones of the opposite cathode surfaces, resulting in a 100-1000 times 
increase in plasma density. High-density plasma, typical for hollow cathodes, is based on efficient avalanche multiplication of electrons, known as the hollow cathode effect $[21,22]$.

The RF hollow cathode deposition system is presented next. The DLC films were deposited on the p-type silicon (100) substrates. The influence of RF power on the deposition rate and the properties of DLC films was also investigated.

\section{Experimental details}

The schematic diagram of the hollow cathode deposition system is shown in Fig. 1. Two general configurations of a hollow cathode are a cylindrical tube or two parallel plates. The latter was used in this experiment. A water cooled stainless steel plate was attached to the spinner rack by three metallic rods. Two plates can rotate with a variable speed, ranging from 600 to $6000 \mathrm{rph}$. The exposed face of both cathodes is $180 \mathrm{~mm}$ in diameter, and the distance between them is adjustable. One or both cathode plates can serve as the substrate table. In this experiment the upper electrode supported the p-type Si (100) substrate, as shown in Fig. 1.

At $2 \mathrm{~kW}$ maximum power and $4 \mathrm{kV}$ maximum self-bias matching networks, a $500 \mathrm{~W}$ RF generator was used as the power supply for the RF hollow cathode. Feed gases, argon and ethane, flowing into the deposition chamber are controlled by the two mass flow controllers.

Before the RF hollow cathode process, silicon substrates were cleaned in acetone and alcohol for $15 \mathrm{~min}$, respectively. The base pressure of $6 \times 10^{-3}$ Pa was achieved in the vacuum chamber using rotary and molecular pumps. Argon ion bombardment for 5 min was necessary to clean the substrates further, just before the DLC film deposition. Ethane was used as the precursor gas, and argon as the ionization gas. The corresponding flow rates were fixed at $45 \mathrm{sccm}$ and $30 \mathrm{sccm}$, respectively. The distance between the two plates was $45 \mathrm{~mm}$, and the rotation speed was $600 \mathrm{rph}$. A series of DLC films has been deposited under different RF power and pressure, ranging between $20 \mathrm{~W}$ and $100 \mathrm{~W}$ and $0.75 \mathrm{~Pa}$ and $4 \mathrm{~Pa}$, respectively. Table 1 shows the details of the experimental parameters.

To facilitate measurement of DLC film thickness, a step was made during deposition. Film thickness was determined by a Dectak 150 surface profiler. The surface and cross-section morphology of DLC films was observed by a field emission scanning electron microscope (FE-SEM, SUPRA 55). Structural characterization of the films was achieved by Micro-Raman spectroscopy. The nanohardness and Young's modulus were measured by means of depth-sensing indentation, carried out with a Nanoindenter XP from MTS Systems.
Table 1

Deposition conditions of DLC films.

\begin{tabular}{ll}
\hline Base pressure & $6 \times 10^{-3} \mathrm{~Pa}$ \\
Total pressure & $0.75 \mathrm{~Pa}, 1.5 \mathrm{~Pa}, 2.5 \mathrm{~Pa}, 4 \mathrm{~Pa}$ \\
Argon flow & $45 \mathrm{sccm}$ \\
Ethane flow & $30 \mathrm{sccm}$ \\
Deposition time & $40 \mathrm{~min}$ \\
Cathode-to-cathode distance & $45 \mathrm{~mm}$ \\
Rotation speed & $600 \mathrm{rph}$ \\
RF power & $20 \mathrm{~W}, 30 \mathrm{~W}, 50 \mathrm{~W}, 80 \mathrm{~W}, 100 \mathrm{~W}$ \\
\hline
\end{tabular}

\section{Results and discussion}

\subsection{Film deposition rate}

As seen in Fig. 2 (a) and (b), DLC film deposition rates increased from 17 to $39 \mathrm{~nm} / \mathrm{min}$ with an RF power increase from $20 \mathrm{~W}$ to $100 \mathrm{~W}$, and to $45 \mathrm{~nm} / \mathrm{min}$ with the pressure increase to $4 \mathrm{~Pa}$. DLC films were deposited in a single cathode configuration, the conventionally used RF-PECVD method. It turns out that under the same deposition conditions, the deposition rate, obtained by a general RF-PECVD process, ranged from 4 to $10 \mathrm{~nm} / \mathrm{min}$ [16], which is about one fourth of that achieved by a hollow cathode process. The degree of plasma ionization increased with the RF power and pressure, requiring a higher plasma density, which resulted in a higher deposition rate.

This large increase in the deposition rate of the hollow cathode process is due to the enhancement in the plasma density. From Fig. 1, one can see that the obvious difference between a RF-PECVD and a hollow cathode method is the number of cathodes. Two parallel plate cathodes constrain electrons in a closed area. During the hollow cathode discharge process, its geometry promotes oscillations of hot electrons inside the cathode, thereby enhancing ionization, ion bombardment of the inner walls and other subsequent processes. Thus, a higher plasma density results in a higher deposition rate, compared with the single cathode.

The substrate is subject to a negative $D C$ self-bias voltage $V_{B}$, which was controlled by changing the RF input power. The negative self-bias voltage increases with the RF power due to increased plasma ionization. When a hollow cathode effect was achieved, $V_{B}$ dropped for the same experimental conditions. The variation of $V_{B}$ with $R F$ input power in RF-PECVD and RF hollow cathode deposition is shown in Fig. 3 (a) and (b). Comparing Fig. 3 (a) and (b), one can see that the value of $V_{B}$ is much smaller in the RF hollow cathode deposition mode than in the RF-PECVD for the same RF power and pressure. This is due to the higher

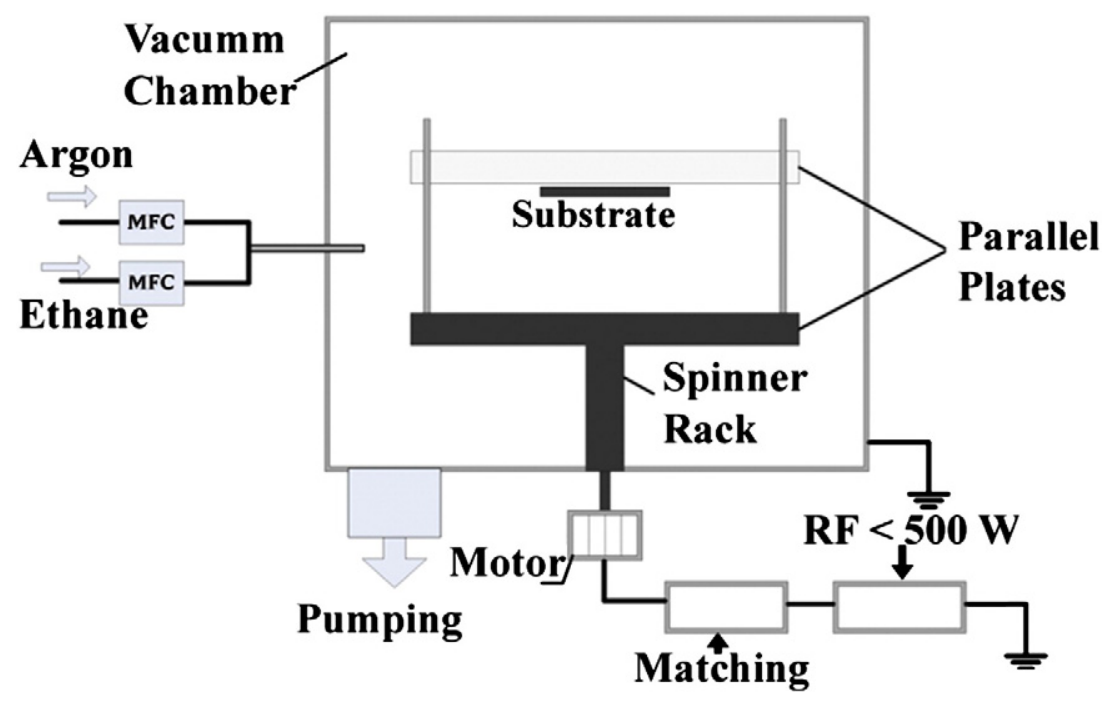

Fig. 1. Schematic diagram of the hollow cathode apparatus. 

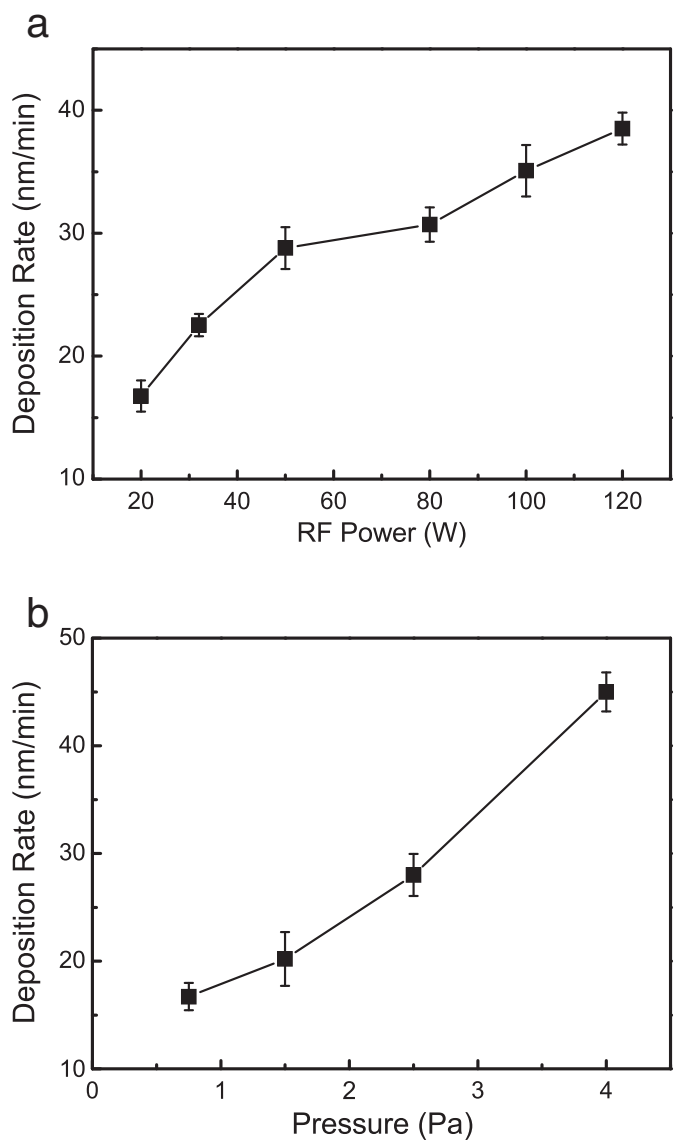

Fig. 2. Film deposition rate variation with: (a) RF power and (b) pressure.

dissociation of ions in the RF hollow cathode deposition mode, which rises the ion current, and decreases the negative DC self-bias voltage. The deposition rate increased by nearly four times.

\subsection{SEM characterization}

In order to compare properties of DLC films deposited with different preparation modes, a series of samples was made. The surface and cross-section SEM images, shown in Fig. 4, illustrate the effect of RF power on the surface and cross-section topography of DLC films deposited during RF hollow cathode discharge process, respectively. Fig. 4(a), (c), (e) shows the surface images of DLC films deposited at $30 \mathrm{~W}, 50 \mathrm{~W}$, and $100 \mathrm{~W}$. One can see that the surfaces of the specimens are getting much smoother at higher RF power, while the carbon clusters on the surface are becoming larger. The surface average roughness is $10.5 \mathrm{~nm}, 4.9 \mathrm{~nm}$, and $2.8 \mathrm{~nm}$, respectively. The cross-sectional images in Fig. 4(b), (d), (f) show that the films are becoming denser with increasing deposition RF power. X-ray reflectivity experiments were performed on select samples deposited at RF power of $30 \mathrm{~W}$ and $100 \mathrm{~W}$, and show that the density of DLC films is increasing from 1.75 to $2.16 \mathrm{~g} \mathrm{~cm}^{-3}$, respectively, indicating that DLC films deposited at high RF power are denser.

\subsection{Raman spectroscopy}

Raman spectroscopy provides important information about bonding structure of DLC films. The $532 \mathrm{~nm}$ line of an argon-ion laser was used for all measurements. Fig. 5 shows the Raman spectra of DLC films as a function of RF power. The spectra consists of the main $G$ band at $1530 \mathrm{~cm}^{-1}$ and a broad shoulder D band at $1370 \mathrm{~cm}^{-1}$ (the peak around $970 \mathrm{~cm}^{-1}$ is due to the Si substrate), a feature typical for DLC films. The $\mathrm{G}$ and $\mathrm{D}$ bands are due to $\mathrm{sp}^{2}$ sites. The $\mathrm{G}$ band is associated
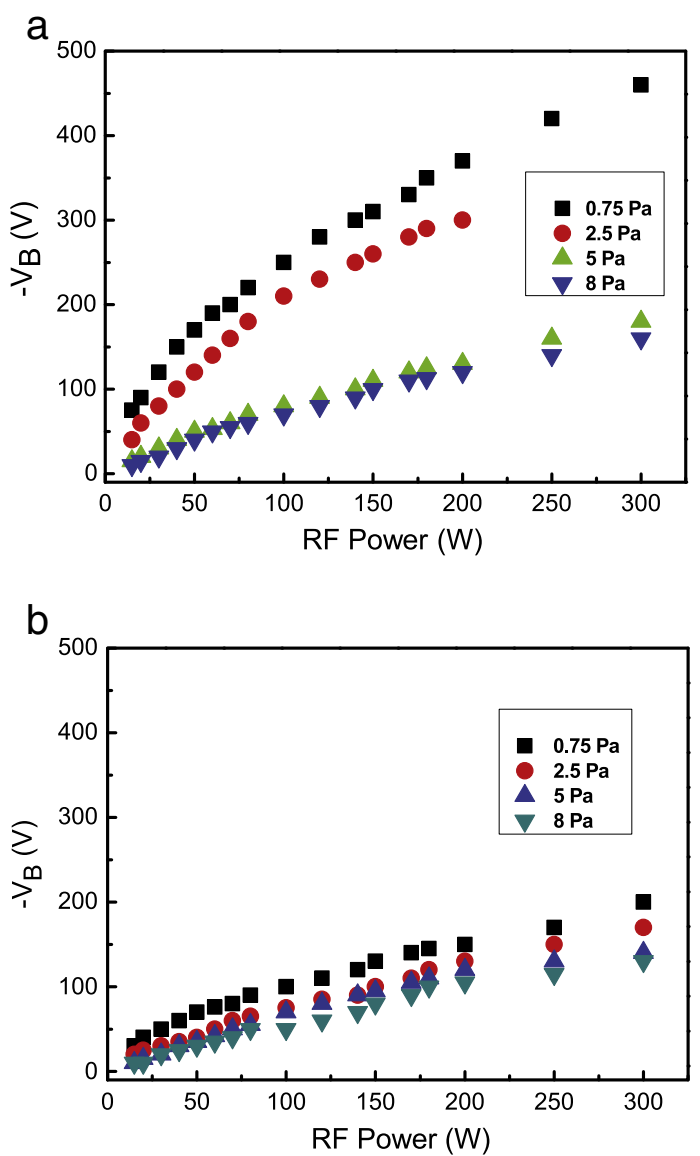

Fig. 3. The self-bias voltage change with different RF power in: (a) RF-PECVD, (b) RF hollow cathode deposition mode.

with the bond stretching of all pairs of $\mathrm{sp}^{2}$ atoms in both rings and chains. The $\mathrm{D}$ band is related to the breathing modes of $\mathrm{sp}^{2}$ atoms in rings. Each Raman spectrum was fitted with two Gaussian peaks. The fitting results are summarized in Fig. 6. Integral intensity $\mathrm{I}_{\mathrm{D}} / \mathrm{I}_{\mathrm{G}}$ ratios were calculated from the ratio of the $D$ and $G$ peaks areas, which signifies the $\mathrm{sp}^{3} / \mathrm{sp}^{2}$ ratio in the films. It's seen in Fig. 6 that the $\mathrm{I}_{\mathrm{D}} / \mathrm{I}_{\mathrm{G}}$ ratio tends to decrease with the RF power. The $\mathrm{I}_{\mathrm{D}} / \mathrm{I}_{\mathrm{G}}$ ratio decrease always reflects an increase of $\mathrm{sp}^{3}$ content [23-26], thus there is a larger $\mathrm{sp}^{3}$ fraction for DLC films deposited under a higher power. With the lower $I_{D} / I_{G}$ ratio, the $G$ band position shifts towards higher frequencies, seen in Fig. 6. Differently, however, for most DLC films deposited by plasma-enhanced chemical vapor deposition, the $\mathrm{I}_{\mathrm{D}} / \mathrm{I}_{\mathrm{G}}$ ratio decrease usually goes together with a decrease of the $G$ band position. According to reference [23], the increase of the $G$ peak position with $\mathrm{sp}^{3}$ content, is due to the change of $\mathrm{sp}^{2}$ configuration from rings to olefinic groups, with their higher vibration frequencies lying above the band limit of graphite. This effect is larger than the tendency of the $G$ band to fall due to mixing with lower frequency $\mathrm{sp}^{3}$ modes. In addition, the width of the $\mathrm{G}$ band is believed to be proportional to the bond angle disorder at $\mathrm{sp}^{2}$ sites [23], and this conclusion is also reflected in our experimental results in Fig. 6.

\subsection{Nanohardness}

The maximum load of $5 \mathrm{mN}$ was used for nanoindentation measurements in order to avoid substrate effects for all films. The hardness (H) and Young's modulus (E) variations with RF power for DLC films are shown in Fig. 7. Hardness and Young's modulus have been known to vary over a wide range of $\mathrm{sp}^{3} / \mathrm{sp}^{2}$ bonding ratios. The hardness of diamond can reach $100 \mathrm{GPa}$ due to the $\mathrm{sp}^{3}$ bonded carbon atoms, but the graphite hardness may go up to $7 \mathrm{GPa}$ due to the $\mathrm{sp}^{2}$ 

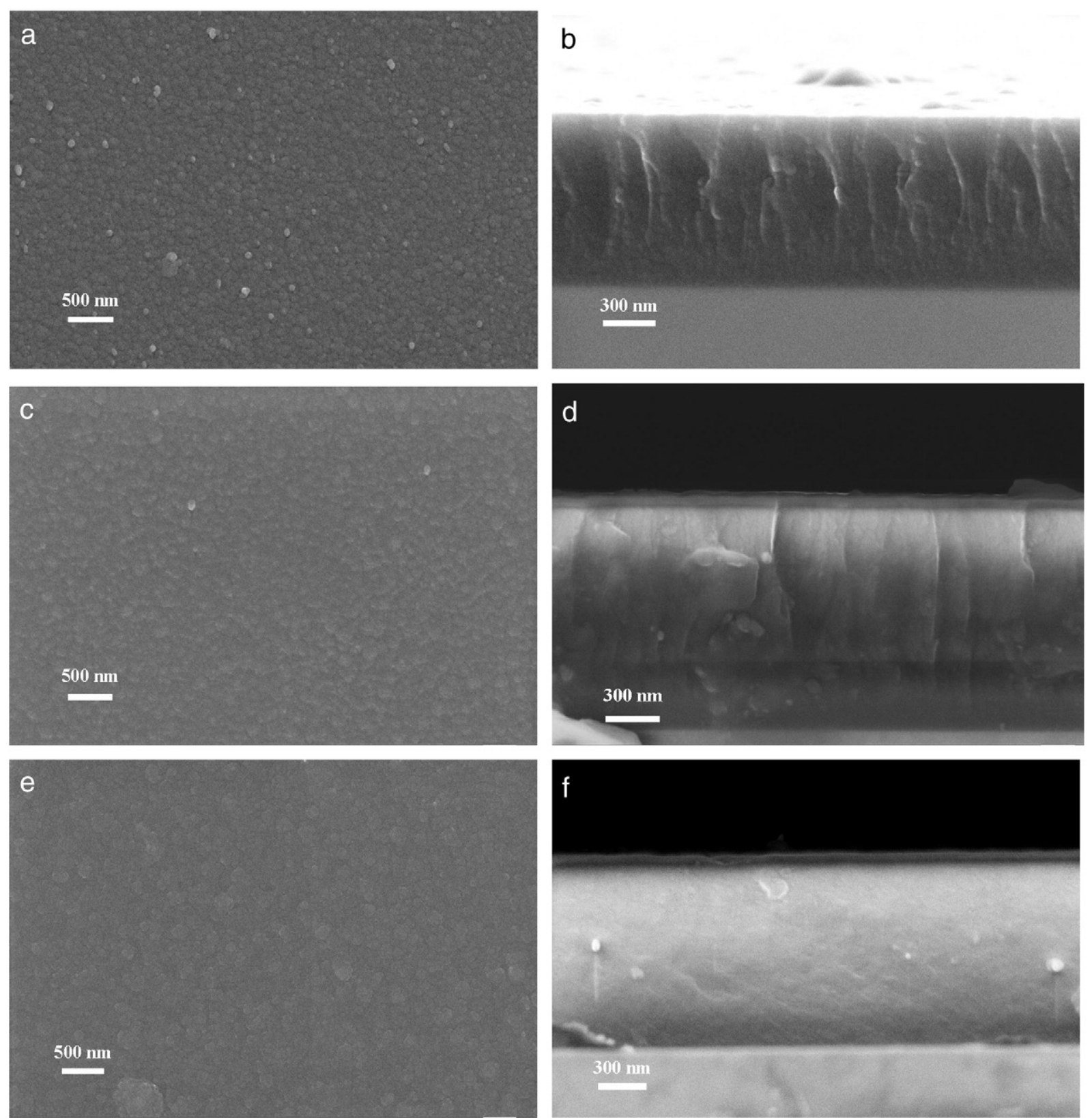

Fig. 4. SEM images of DLC films: (a) surface at $30 \mathrm{~W}$, (b) cross-section at $30 \mathrm{~W}$, (c) surface at $50 \mathrm{~W}$, (d) cross-section at $50 \mathrm{~W}$, (e) surface at $100 \mathrm{~W}$ and (f) cross-section at $100 \mathrm{~W}$.

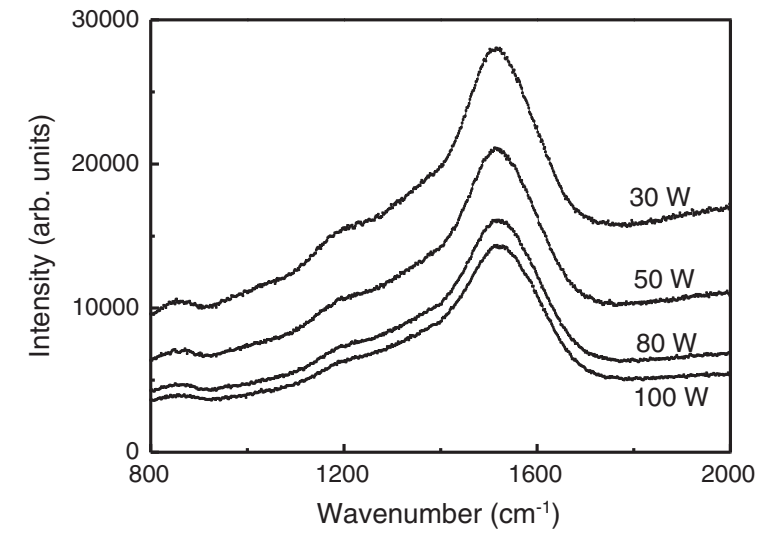

Fig. 5. Raman spectra of the DLC films deposited at different RF power.

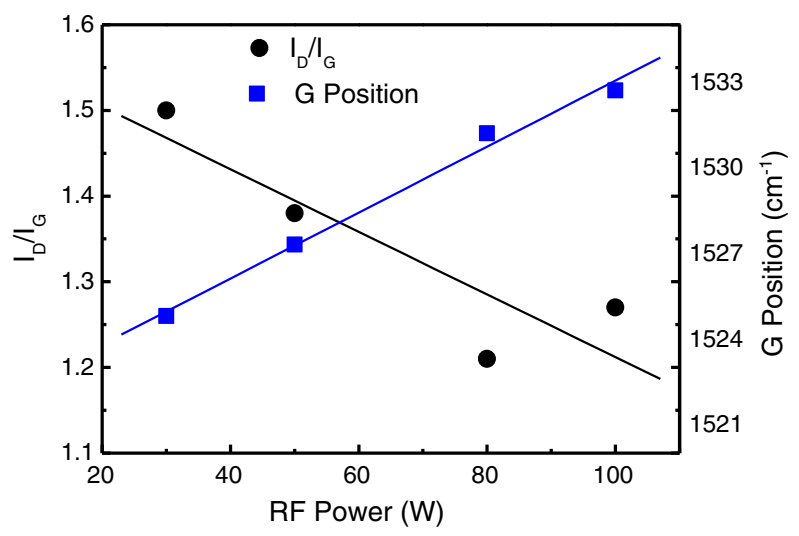

Fig. 6. Variation of $I_{D} / I_{G}$ ratio and $G$ position with RF power for DLC films. 


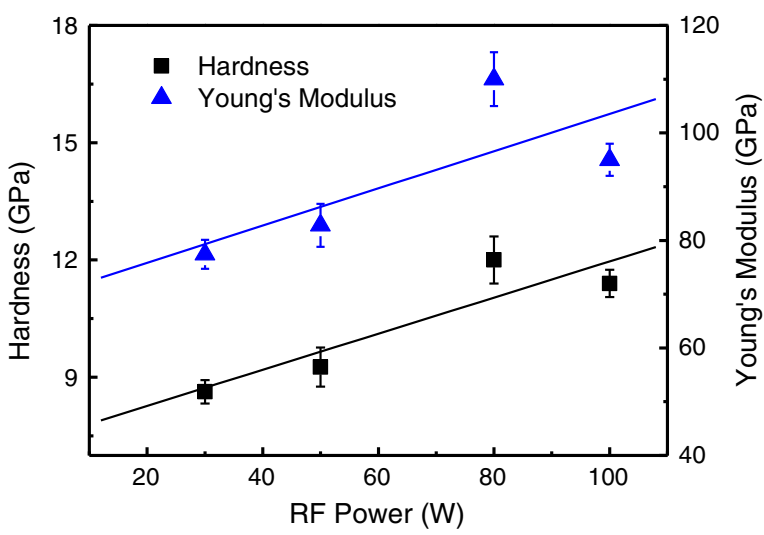

Fig. 7. Nanohardness (H) and Young's modulus (E) values of the DLC films deposited at different RF powers.

bonded carbon atoms. In this experiment, the hardness of DLC films varies from $8.7 \mathrm{GPa}$ to $12 \mathrm{GPa}$. The hardness was measured at different points of the sample surface, and there was not much difference in the measured values. The high hardness of DLC films is due to the $\mathrm{sp}^{3}$ fraction. It can be seen that the $\mathrm{H}$ and $\mathrm{E}$ values show agreement with the Raman analysis. The hardness reaches the maximum when the $I_{D} / I_{G}$ ratio is the minimum at $80 \mathrm{~W}$, and $E$ values follow the same trend, signifying the highest $\mathrm{sp}^{3}$ fraction in the film. In Fig. 6 , the $\mathrm{I}_{\mathrm{D}} / \mathrm{I}_{\mathrm{G}}$ ratio of DLC films deposited at $80 \mathrm{~W}$ is about 1.2 , but the $\mathrm{I}_{\mathrm{D}} / \mathrm{I}_{\mathrm{G}}$ ratio of DLC films deposited at $100 \mathrm{~W}$ is about 1.3 . The $\mathrm{I}_{\mathrm{D}} / \mathrm{I}_{\mathrm{G}}$ ratio increase reflects a decrease of $\mathrm{sp}^{3}$ content, which means that the hardness is much lower for the films deposited at $100 \mathrm{~W}$ than those deposited at $80 \mathrm{~W}$.

\section{Conclusions}

DLC films were deposited on the p-type Si (100) substrates using a custom-built RF hollow cathode deposition system, with ethane as the precursor gas. The deposition rate is four times that of the conventional plasma-enhanced chemical vapor deposition process (with similar deposition parameters), and increases linearly with the RF power. Raman spectroscopy measurements illustrate that the $\mathrm{I}_{\mathrm{D}} / \mathrm{I}_{\mathrm{G}}$ ratio decreases with the RF power increase, while the $G$ band position shifts to higher frequencies and the $\mathrm{G}$ band width broadens. These variations with RF power are related to the change of $\mathrm{sp}^{3}$-bonded carbon fraction and $\mathrm{sp}^{2}$ configuration in the film structure. Finally, the nanohardness and Young's modulus values show good agreement with the Raman analysis.

\section{Acknowledgments}

This work was supported by National Nature Science Foundation of China $(51001013,51271022)$, Fok Ying Tung Education Foundation (132001) and the Fundamental Research Funds for the Central Universities.

\section{References}

[1] K.P. Shaha, Y.T. Pei, C.Q. Chen, J.Th.M. De Hosson, Thin Solid Films 519 (2010) 1618.

[2] W. Tillmann, E. Vogli, F. Hoffmann, Thin Solid Films 516 (2007) 262.

[3] Q. Zeng, O. Eryilmaz, A. Erdemir, Thin Solid Films 519 (2011) 3203.

[4] C.A. Taylor, M.F. Wayne, W.K.S. Chiu, Thin Solid Films 429 (2003) 190.

[5] X. Pang, H. Yang, K. Gao, Y. Wang, A.A. Volinsky, Thin Solid Films 519 (2011) 5353.

[6] H. Ito, K. Yamamoto, M. Masuko, Thin Solid Films 517 (2008) 1115.

[7] H. Miki, T. Takeno, T. Takagi, Thin Solid Films 516 (2008) 5414.

[8] V. Singh, J.C. Jiang, E.I. Meletis, Thin Solid Films 489 (2005) 150

[9] Y.-Y. Chang, Da-Y. Wang, W.T. Wu, Thin Solid Films 420 (421) (2002) 241.

[10] M. Kalin, J. Vižintin, Thin Solid Films 515 (2006) 2734.

[11] D. Caschera, F. Federici, L. Pandolfi, S. Kaciulis, M. Sebastiani, E. Bemporad, G. Padelett, Thin Solid Films 519 (2011) 3061.

[12] S. Miyagawa, S. Nakao, K. Saitoh, K. Baba, Y. Miyagawa, Surf. Coat. Technol. 128 (129) (2000) 260.

[13] N.A. Marks, J.M. Bell, G.K. Pearce, D.R. McKenzie, M.M.M. Bilek, Diam. Relat. Mater. 12 (2003) 2003.

[14] Y. Gao, X. Chen, S. Gupta, K.D. Gillis, S. Gangopadhyay, Biomed. Microdevices 10 (2008) 623.

[15] S. Chowdhury, M.T. Laugier, I.Z. Rahman, J. Mater. Process. Technol. 153 (154) (2004) 804.

[16] X. Pang, H. Yang, S. Shi, K. Gao, Y. Wang, A.A. Volinsky, J. Mater. Res. 25 (2010) 2159.

[17] Z. Sun, X. Shi, E. Liu, Thin Solid Films 355-356 (1999) 146

[18] K. Baba, R. Hatada, Thin Solid Films 506-507 (2006) 55.

[19] K. Azuma, E. Fujiwara, M. Yatsuzuka, Thin Solid Films 506-507 (2006) 68.

[20] N.A. Morrison, S.E. Rodil, A.C. Ferrari, J. Robertson, W.I. Milne, Thin Solid Films 337 (1999) 71.

[21] N.A. Morrison, S. Muhl, S.E. Rodil, A.C. Ferrari, M. Nesladek, W.I. Milne, J. Robertson, Phys. Status Solidi A 172 (1999) 79.

[22] V.V. Gorin, Ukr. J. Phys. 53 (2008) 366.

[23] X.L. Peng, Z.H. Barber, T.W. Clyne, Surf. Coat. Technol. 138 (2001) 23.

[24] G. Capote, L.G. Jacobsohn, M.D. Michel, C.M. Lepienski, A.L. Vleira, D.F. Franceschini, Diam. Relat. Mater. 16 (2007) 616.

[25] A.C. Ferrari, J. Robertson, Phys. Rev. B 62 (2000) 14095

[26] A.C. Ferrari, Diam. Relat. Mater. 11 (2002) 1053. 